\title{
O encontro entre o Núcleo de Apoio à Saúde da Família e as equipes de Saúde da Família: a produção de um coletivo cuidador
}

\section{| ${ }^{1}$ Kátia Santos de Oliveira, ${ }^{2}$ Rossana Staevie Baduy, ${ }^{3}$ Regina Melchior |}

Resumo: O Núcleo de Apoio à Saúde da Família (NASF) foi criado com a finalidade de reorganizar a assistência à saúde e auxiliar na qualificação do SUS. A organização do processo de trabalho do NASF depende da existência de espaços coletivos, de momentos de encontros em que trabalhadores possam estar juntos para implementação de açôes mais qualificadas, aumentando a capacidade resolutiva das equipes. Este artigo tem como objetivo analisar os processos vivenciados pela equipe NASF para produção de momentos de encontro como meio de produzir apoio às equipes de saúde da família. Pesquisa de abordagem do tipo qualitativa, que utilizou no trabalho de campo observação e grupo focal. Como resultados, são apresentados os processos vividos pela equipe NASF para a produção de coletivo, descrevendo como foi construído o espaço da reuniáo de matriciamento e os processos vividos que contribuíram para isso, como momentos informais de encontros, como o do cafezinho. A equipe NASF buscava alternativas de integração, no entanto, sua prática era capturada pelo processo de trabalho operante e pelo modelo hegemônico. A aposta em encontros intercessores, onde saberes, tanto técnicos como os da vida, sejam compartilhados é um caminho a ser trilhado na produção de um coletivo.

> Palavras-chave: Saúde da Família; apoio; produção de coletivo; cuidado em saúde.

\author{
1 Centro de Ciências da Saúde, \\ Universidade Estadual de \\ Londrina. Londrina-PR, Brasil \\ (katia.fit@gmail.com). \\ ORCID: 0000-0003-3622-7955 \\ ${ }^{2}$ Centro de Ciências da Saúde, \\ Universidade Estadual de \\ Londrina. Londrina-PR, Brasil \\ (robaduy@gmail.com). \\ ORCID: 0000-0003-4914-653X \\ ${ }^{3}$ Centro de Ciências da Saúde \\ Universidade Estadual de \\ Londrina. Londrina-PR, Brasil \\ (reginamelchior@gmail.com) \\ ORCID: 0000-0002-7198-601X.
}

Recebido em: 21/01/2019 Revisado em: 06/05/2019 Aprovado em: 25/05/2019 


\section{Introdução}

A atenção básica $(A B)$ em saúde é, muitas vezes, vista como o lugar de uma atenção simplificada e pouco complexa. No entanto, na $\mathrm{AB}$ os trabalhadores se deparam com uma grande diversidade de agravos, tanto agudos como crônicos, que implicam um rol de atos de cuidado que vão desde as práticas protocolares de uma ação programática às ambulatoriais e curativas, passando pelo cuidado de famílias em situação de risco e vulnerabilidade, ações de promoção e educação em saúde, participaçáo no controle social, chegando até a clínica da saúde mental e às demandas do contexto dos programas de assistência social (MEDEIROS, 2015).

Além de ser considerada a principal porta de entrada para o SUS, também é tida como ordenadora da assistência e responsável pelo atendimento horizontal e longitudinal (BRASIL, 2012). As diversas ações desenvolvidas e as responsabilidades atribuídas reforçam quão complexo é este nível de atenção à saúde. Por esses e outros motivos, a prática da $\mathrm{AB}$ está longe de poder ser considerada algo simples.

A Estratégia Saúde da Família (ESF) foi pensada para ampliar o acesso da população e possibilitar uma atuação fortemente centrada nos territórios e nas residências. Para isso, iniciou-se com a atuação de equipes mínimas, muito próximas das equipes que já atuavam na AB (BRASIL, 2007; BRASIL, 2012). No entanto, logo ficou evidente a necessidade de outros profissionais, para que se tivesse uma ampliação dos olhares e maior possibilidade de se aproximar do princípio da integralidade (GIL, 2006; FRANCO e MERHY, 2007).

Nesse sentido, o Ministério da Saúde (MS), por meio da portaria GM n. 154, de 24 de janeiro de 2008, criou o Núcleo de Apoio à Saúde da Família (NASF), com a finalidade de reorganizar a assistência à saúde no que diz respeito à atenção básica e auxiliar na qualificação do SUS (BRASIL, 2008). Assim, o NASF veio para contribuir com os profissionais da $\mathrm{AB}$, tendo como preceito básico um trabalho interdisciplinar e de apoio, atuando de acordo com as peculiaridades regionais, com o objetivo de oferecer uma atenção à saúde mais eficiente, e que inclui profissōes e áreas até então não contempladas no âmbito das equipes na ESF, tendo como responsabilidade central atuar e reforçar as diretrizes da AB (BRASIL, 2010).

O Caderno de Atenção Básica número 27, publicado em 2010, dispóe sobre as diretrizes do NASF, descrevendo as atribuiçôes e características de trabalho desses núcleos. Dentre elas, apresenta o apoio matricial, que se baseia, principalmente, nos 
conceitos de Campos (1999) e Campos e Domitti (2007), que pressupóem a inserção do apoio matricial como perspectiva de mudança e reorganização do trabalho em saúde, com foco nos contratos de gestáo.

A proposta de atuação do NASF prioriza o trabalho compartilhado com as equipes de Saúde da Família (eSF) e tem por objetivo transpor a lógica fragmentada, e ainda hegemônica, no cuidado à saúde, com trabalhos pautados de acordo com novas formas de arranjos organizacionais (CAMPOS; DOMITTI, 2007; BRASIL, 2010).

O NASF, em seu desenho original, traz uma ótica integradora, que pretende transformar a lógica tradicional dos sistemas de saúde: encaminhamentos, referências e contrarreferências, protocolos e centros de regulação. Os efeitos burocráticos e pouco dinâmicos dessa lógica tradicional podem vir a ser atenuados por açóes horizontais que integrem os componentes das equipes e seus saberes nos diferentes níveis assistenciais (CHIAVERINI, 2011; OLIVEIRA; CAMPOS, 2015). Podendo então ser entendido como alternativa ao vertical, para produzir relaçôes horizontais entre profissionais de distintas áreas/projetos e campos de conhecimento (BERTUSSI, 2010).

Dessa forma, a organização do processo de trabalho do NASF depende da existência de espaços coletivos, ou seja, do estabelecimento de momentos de encontros em que trabalhadores possam estar juntos para que haja a implementação de açóes mais qualificadas, aumentando a capacidade resolutiva das equipes (DOMITTI, 2006; OLIVEIRA; CAMPOS, 2015). Este é um dos maiores desafios enfrentados pelas equipes NASF, que, além de construir um processo de trabalho até então inexistente na $\mathrm{AB}$, precisa criar espaços e formas para desenvolver apoio e compartilhamento de açóes.

Nesse sentido, o trabalho do NASF somente pode ser desenvolvido a partir da construção de momentos relacionais, nos quais, por meio de momentos de encontro, aconteça troca de saberes/afetos entre os profissionais de diferentes áreas ou setores, com o objetivo de aumentar a chance de as equipes estabelecerem relaçóes de cooperação, responsabilizando-se pelas açóes desencadeadas, num processo de produção de integralidade da atenção. O que pode contribuir para a superação de um processo de trabalho focado nos modelos já existentes e pouco resolutivos, passando a centrar seus esforços nos usuários, ultrapassando a produção de procedimentos em si para a produção de saúde em defesa da vida (MERHY, 2002; BERTUSSI, 2010; CASTRO; CAMPOS, 2016). 
Assim, ao centralizar as açôes de saúde no usuário, abrem-se múltiplas possibilidades de produção de ações cuidadoras, desde que se leve em consideração que as necessidades de saúde, trazidas pelos usuários, devem ser o objeto das açôes e o cuidado, o produto delas. Por se tratar, porém, da instituição de um novo processo de trabalho, centrado no trabalho em equipe, interprofissional e multidisciplinar, que se contrapóe a uma forma já arraigada de trabalho uniprofissional e com lógica de encaminhamentos, em uma visão fragmentada do cuidado, as equipes podem encontrar resistências e dificuldades em operacionalizar essa nova prática.

Em 2017, em revisão da Política Nacional de Atenção Básica, por meio da portaria n. 2.436, o NASF passou a ser denominado Núcleo Ampliado de Saúde da Família. Esta portaria faz referência a um propósito de complementar as equipes que atuam na $A B$ e de atuação integrada para dar suporte (clínico, sanitário e pedagógico) aos profissionais das eSF e AB (BRASIL, 2017).

Este artigo, que faz parte de uma pesquisa de mestrado que buscou compreender a implantação do NASF para a produção do cuidado em saúde, tem como objetivo analisar os processos vivenciados pela equipe NASF para produção de momentos de encontro e de coletivo, como meio de produzir apoio às equipes de saúde da família. A pesquisa foi realizada durante a vigência da portaria GM n. 154, de 2008, porém, de qualquer modo, acreditamos que há várias formas de se operacionalizar a proposta de integração, e que o apoio entre as equipes seja indispensável em qualquer arranjo.

\section{Percurso metodológico}

Trata-se de parte de uma pesquisa realizada na regiáo sul do Brasil, que utilizou abordagem do tipo qualitativa e que obteve financiamento da Fundaçáo Araucária, por meio de edital do PPSUS.

O município referente a este recorte, no ano do estudo, organizava sua rede de AB com 52 Unidades Básicas de Saúde (UBS) distribuídas nas regióes urbana e rural, com 75 equipes de Saúde da Família e 15 equipes do Programa de Agentes Comunitários de Saúde (PACS), a atenção odontológica era desenvolvida em 45 UBS. A cobertura, pela ESF, era de $52 \%$ da populaçâo total. Contava com dez equipes NASF, que se distribuíam de acordo com a proximidade entre as UBS e número de eSF, e em duas unidades básicas, atuava uma equipe da Residência Multiprofissional em Saúde da Família (RMSF). Na área rural não havia equipe NASF completa, 
só a inserção da fisioterapia. O município tinha equipes NASF compostas por um profissional de educação física, um farmacêutico, um nutricionista, um psicólogo e dois a três fisioterapeutas. Os fisioterapeutas tinham carga horária semanal de 30 horas e os demais profissionais, de 40 horas.

Participaram do estudo cinco trabalhadores que compunham uma equipe NASF. O critério para a escolha da equipe, para a pesquisa, foi a indicação, pela Diretoria de Atenção Primária em Saúde, de uma equipe de NASF que estivesse desenvolvendo (com regularidade) açôes de apoio matricial nas UBS onde atuavam. Utilizaram-se, no trabalho de campo, estratégias de observação, com registro em diário de campo e entrevista coletiva por meio de grupo focal. A fase de observação se deu de setembro a dezembro de 2012, com acompanhamento dos trabalhadores nos diversos locais em que atuavam.

Finalizada a fase de observaçóes, foi realizado um grupo focal com esta equipe. O grupo seguiu um roteiro semiestruturado com questionamentos relacionados à trajetória do NASF desde a implantaçáo no município, à organização e à interação da equipe no trabalho desenvolvido nas UBS, ao apoio matricial desenvolvido e ao apoio que recebiam da gestão. O grupo focal foi conduzido por uma das autoras, que também participou da fase de observações, assumindo o papel de moderadora da discussão, e contou com o apoio de três observadores, que auxiliaram com os equipamentos de mídia para gravação, além de realizarem anotaçóes que poderiam auxiliar na análise dos dados, como, por exemplo, reaçôes, gestos corporais, entonação de fala dos participantes, etc. Foi realizado no horário de trabalho, porém, fora das dependências das UBS, evitando assim ruídos e interrupçôes (TRAD, 2009). A gravaçáo foi transcrita pela pesquisadora, moderadora da discussáo.

Para complementar o material levantado no trabalho de campo, foram utilizados documentos produzidos pela própria equipe que tinha alguma relação com as atividades por eles desenvolvidas, como, por exemplo, registro em prontuário, relatórios de produção, cadernos com registros de atividades desenvolvidas nas UBS, fichas de matriciamento, dentre outros.

Para caracterização dos entrevistados, cada profissional preencheu uma ficha com informaçóes de interesse para a pesquisa. E foram identificados com nome de flores: Amarílis, Antúrio, Gardênia, Gérbera e Tulipa.

Foram utilizados na análise o produto das observações registradas no diário de campo e a transcrição do grupo focal, complementados pelos documentos 
apresentados. O registro das observaçóes e a transcrição foram lidos e, em seguida, elaborou-se uma síntese dos registros das observaçóes e uma síntese do grupo focal. Após discussão entre os pesquisadores, foram identificadas categorias de análise do material produzido, entendidas aqui como ideias centrais das narrativas e textos produzidos durante a observaçáo que funcionam para dar visibilidade ao que foi vivenciado em campo.

Toda a pesquisa, desde sua concepção, foi permeada pelo referencial teórico da Micropolítica do Trabalho e o Cuidado em Saúde (MERHY, 2002; MERHY; FEUERWERKER, 2008; http://saudemicropolitica.blogspot.com.br/).

Durante todo o processo, foram respeitados os princípios éticos da pesquisa. O estudo foi cadastrado com Certificado de Apresentaçáo para Apreciação Ética (CAAE) n. 06127012.7.0000.5231 e aprovado por Comitê de Ética em Pesquisa sob Parecer n. 93.228, em 31 de agosto de 2012.

\section{Resultados}

\section{A equipe NASF}

Originalmente, a equipe NASF estudada era composta por sete trabalhadores, mas durante o período de trabalho de campo, a equipe contava apenas com um farmacêutico, dois fisioterapeutas, um nutricionista e um profissional de educação física. Faltavam um psicólogo e um fisioterapeuta.

Dos cinco trabalhadores que compunham a equipe, apenas um era do sexo masculino. A idade variava de 24 a 41 anos. Com relação ao tempo de conclusão da graduação, um profissional tinha três anos, dois tinham seis anos, outro, dez anos, e o último, quinze anos de formado. Além da graduação, quatro deles possuíam especialização em áreas afins com suas profissôes. E nas áreas de saúde pública, saúde coletiva ou saúde da família, um já havia concluído pós-graduação e os demais estavam em fase de conclusão.

Nenhum trabalhador mantinha outro vínculo empregatício além do NASF, todos, porém, já haviam tido experiências em outras áreas relacionadas as suas profissōes. Três estavam desde o início da implantação do NASF, em 2008; os outros dois atuavam na equipe há um ano. Todos passaram por processos de seleção e mantinham vínculo empregatício, com contrato por prazo determinado, não estatutário. Essa equipe NASF apoiava 4 UBS, em um total de 10 eSF. 


\section{Processos vividos para a produçáo de coletivo... a reuniáo de matriciamento}

A equipe NASF se organizava com os trabalhadores distribuídos em períodos do dia em cada uma das unidades. Esta foi uma solicitação feita pelas coordenadoras das UBS, que justificavam dificuldades de estrutura física para que a equipe NASF ficasse junto. Houve, porém, um movimento desta equipe para que, no mínimo, dois deles estivessem na mesma unidade em cada período: "a gente tentou equilibrar isso, de estar em certos momentos, pelo menos uma vez na semana, em cada unidade e se encontrar, principalmente para as atividades em grupo [...] (Amarílis)."

Este era um processo que permitia aos profissionais do NASF estar pelo menos duas vezes por semana em cada unidade, mas que trazia algumas dificuldades em seu processo de trabalho, como, por exemplo, o deslocamento entre uma unidade e outra em horário de almoço e a constante rotatividade entre as UBS e eSF. Isso fazia com que permanecessem pouco tempo em cada serviço, o que para a equipe NASF era considerado um complicador, tanto para dar continuidade às atividades iniciadas, quanto para o estabelecimento de vínculo com os trabalhadores das diversas equipes.

A equipe NASF foi idealizada, inicialmente, com o objetivo de aumentar a resolutividade e a abrangência de açóes e serviços oferecidos pelas eSF (BRASIL, 2008). No entanto, ao chegar aos serviços de saúde, essa equipe precisava se constituir enquanto coletivo. Segundo Ceccim (2005), a noção de coletivo vem dar conta da disposição em grupo de pessoas interligadas por uma tarefa que constitui finalidade produtiva; complementada pela noçâo de coletivo organizado que exige desse agrupamento de pessoas uma convergência, uma composição de roda.

Como estavam em dias e horários diferentes em cada unidade, pouco conseguiam se encontrar com a eSF: "[...] Inicialmente, a gente tentou participar das reuniôes de equipe (SF), mas essa questão do deslocamento era impossível; que se a gente conseguisse estar junto com eles em todas as reuniôes semanais que eles fazem seria muito melhor [...]" (Amarílis). Durante o processo de organização do trabalho, a equipe NASF cada vez mais percebia a necessidade de ter momentos em que estivessem juntos para que seu trabalho, enquanto equipe de apoio às eSF, pudesse acontecer. Consideravam importante tempo e espaço para a construçáo de pactuaçôes/parcerias entre as equipes e profissionais envolvidos: “[...] na verdade, eu 
acho que o nosso horário deveria ser de acordo com o horário das reuniôes de equipe (SF), (...) mas a gente não tem essa prioridade, daí a gente teve que criar espaços para conseguir se aproximar deles [...]" (Amarílis).

$\mathrm{O}$ encontro entre equipes e trabalhadores se faz necessário, primeiramente, para que estes se identifiquem em suas proximidades e diferenças e assim se constituam e se reconheçam enquanto equipe. Em todos os processos de trabalho conjunto, de produção em grupo, existe a necessidade de que os trabalhadores se encontrem para discutir, refletir sobre o trabalho, sobre situaçôes vivenciadas, e assim criar processos com objetivos em comum, que possibilitem a ampliação e aumento da resolutividade das açóes desenvolvidas pela eSF. Ceccim (2005) destaca que, ao nos referirmos a um coletivo organizado, náo estamos falando dos trabalhadores individualmente e nem da sociedade dos trabalhadores, mas de agrupamentos articulados por um fim. O que dá organização ao coletivo organizado não é a identidade entre seus membros, mas seu objetivo de produção (CECCIM, 2005).

Medeiros (2015, p. 1177), em seu estudo sobre matriciamento, afirma que a relação horizontal efetivamente estabelecida entre as equipes NASF e a eSF nos encontros é que define o sucesso para a "construção compartilhada do caso, a consulta conjunta, a educação permanente, a análise institucional”. Enfatiza que somente a criação formal por leis e portarias de uma rede não garante a atualização do encontro colaborativo.

Em outra pesquisa realizada com equipes de atenção domiciliar em um município do Paraná (MERHY, 2013a), identificou-se a importância dos momentos de encontros entre trabalhadores e equipes, para o fortalecimento desta identidade coletiva. Lima et al. (2016) destacam que o encontro, a princípio, pode parecer algo simples, "como compartilhar o mesmo espaço físico ou dividir uma mesa de trabalho", no entanto, é aí que se produzem as memórias coletivas sobre a produção do cuidado de cada família, e é também aí, nas conversas sobre o vivido nos domicílios, entre as anotaçôes nos prontuários, nas organizaçôes das visitas e nas discussóes de mudanças de conduta, que são colocados em análise o cuidado produzido e as propostas de mudanças nos projetos terapêuticos de cada caso. É local também de conflitos e discussóes, é onde o coletivo se monta e desmonta, onde a trama das relaçôes de poder se torna ou não visível (LIMA et al., 2016; MERHY; FEUERWERKER, 2008). 
Com a impossibilidade de participar das reuniôes semanais das eSF, a alternativa encontrada pela equipe NASF foi criar um momento de encontro com as eSF, denominado por eles de reunião de matriciamento. Esta reunião acontecia uma vez por mês em cada UBS, com a proposta de que estivesse presente toda a equipe NASF e a eSF.

Para que isso acontecesse, a equipe NASF negociou com as coordenaçôes das UBS que todos os trabalhadores do NASF estivessem juntos para participar do processo de apoio e que a eSF se organizasse para também participar. Esta foi uma interferência da equipe NASF no processo de trabalho das eSF que propiciou mais encontros entre eles para efetuar o apoio às equipes.

A reunião de matriciamento passou a ser um momento de encontro, em que uma vez por mês todos os profissionais do NASF se reuniam em uma mesma UBS para propiciar apoio às eSF. Foi pensada, inicialmente, com a intenção de que fossem discutidos casos trazidos pela eSF: "[...] como eles têm a reuniáo de equipe deles, a ideia era que discutissem o caso e preenchessem pelo menos a primeira parte da ficha do plano terapêutico, quanto às condiçôes de saúde e socioeconômicas daquela pessoa ou daquela família, e, então, viesse isso pra nós, já pra facilitar a própria discussão do caso [...]” (Amarílis).

Os casos a ser discutidos nessas reuniōes eram aqueles que estavam gerando algum incômodo para determinado trabalhador, para aqueles que se sentiam sem alternativas para resolver o problema ou para a eSF como um todo. O objetivo era elaborar um plano terapêutico, com a participação de todos os trabalhadores. Mas o que se viu foi que, na discussão dos casos, o foco se voltava para as questóes nucleares de cada profissional do NASF ali presente. Por exemplo, o fisioterapeuta pensava de que forma poderia intervir, assim como o farmacêutico, o nutricionista, não era uma discussão de um plano de cuidados centrado nas necessidades do usuário.

Na reunião de matriciamento, discutiu-se sobre um casal de idosos, em que a esposa é
diabética, e o esposo, que também é seu cuidador e responsável por aplicar a insulina, es-
tava com uma lombalgia e por isso estava com dificuldades para aplicar a insulina. O que
ficou 'combinado' é que o farmacêutico fará uma visita para verificar o HGT e como está
a administração da insulina, e orientar sobre. Como esta equipe não tinha fisioterapeuta e
psicólogo, a equipe discutiu que não 'dava pra fazer' outras coisas além de manter a visita
médica (registro diário de campo).

O instante da reunião acabava por fortalecer ainda mais os movimentos núcleocentrados, visto que cada categoria identificava em que poderia contribuir para a 
"resolução" do problema apresentado, chegando ao ponto de ser realizada uma 'espécie' de encaminhamento coletivo ao especialista. $\mathrm{O}$ encontro que acontecia na reunião de matriciamento não era uma produção coletiva, era um momento de produçóes individuais dentro de um espaço coletivo/de um grupo. O mesmo acontecia quando os profissionais estavam sozinhos (em um atendimento individual ou em grupo), suas açôes não reverberavam em açóes que influenciassem no coletivo, em sua maioria os resultados continuavam sendo pensados e produzidos de forma individual.

Eram pouco discutidas estratégias de ampliação das açôes para o campo de cuidado de modo que o saber núcleo-centrado deixasse de ser o foco e o cuidado fosse centrado no usuário, com práticas que ampliassem as possibilidades de matriciamento. Merhy (1998) apresenta a concepção de dimensão cuidadora, como um espaço em que todos realizam a atenção à saúde baseada nas açôes relacionais. Essa dimensão extrapola as ações específicas das profissôes e deve ser enfatizada nas práticas de cuidado à saúde, como forma de ampliação da dimensão cuidadora, tanto para desencadear processos mais conjuntos e partilhados no interior da equipe, quanto para melhorar a eficácia e a adequabilidade da ação de cada núcleo específico com os processos usuários centrados. Com isso, assume-se e reconhece-se que certas abordagens profissionais, em certas circunstâncias, são, de fato, mais eficazes que outras, mas sem fazer disso uma lógica de poder na qual uma profissão se imponha sobre as outras (MERHY, 1998).

Medeiros (2015, p. 1167-68) afirma que a "relação entre as equipes no processo de corresponsabilização pelo cuidado integral da saúde dos usuários costuma produzir, paradoxalmente, um efeito de desresponsabilização". Esse autor considera que tal efeito é decorrente "de um processo de trabalho precarizado e pouco comunicativo entre equipes e saberes", que pode ser verificado a partir de "encaminhamentos excessivos, nas práticas terapêuticas que não privilegiam o vínculo com a equipe da ESF, entre outros".

No campo estudado, embora a equipe NASF tenha se mobilizado para apoiar a eSF na resolução dos casos discutidos, o que predominava era um momento de encaminhamentos ao especialista, que se fazia presente. Por outro lado, o mais comum era a prática tradicional dos profissionais da saúde de prescrever e realizar orientaçôes, que são muito pouco efetivas para a vida do usuário. Quase nada se resolve apenas transmitindo informaçôes, "passando adiante novos acordos ou regras": os combinados precisam ser produzidos, novos arranjos precisam 
ser construídos com a participação de todos. Por isso, é importante trabalhar os coletivos, as suas potências e desconfortos, aprendendo no cotidiano de sua produção (EPS EM MOVIMENTO, 2014).

Não havia um movimento no sentido de ampliar as ofertas e formas de atuação das equipes, como, por exemplo, realizar momentos de atendimentos e visitas compartilhadas, ou a elaboração de planos terapêuticos para os quais o usuário é chamado a participar deste planejamento, o que reforça a ideia de que o espaço do encontro nos serviços de saúde precisa ser melhor aproveitado, sendo uma das possibilidades a introdução da educação permanente em saúde no processo de trabalho, para que o encontro entre trabalhadores produza conexóes, criando-se oportunidades para conversarem, construírem compromissos e arranjos comuns. Uma alternativa é a produção de encontros pautados nas tecnologias leves, em que trabalhadores se fortaleçam, compartilhem o trabalho, a vida, e assim se construam como coletivo, criem novos arranjos, afetem-se com o sofrimento do usuário, sua família e cuidadores (LIMA, et al., 2016).

Uma das limitações para o trabalho compartilhado vem de uma visão e de uma vivência fragmentada do trabalho e do cuidado, condizente com o modelo hegemônico de assistência, que se inicia desde a formação da maioria dos profissionais de saúde, que não é voltada para o trabalho coletivo. Ceccim e Feuerwerker (2004) discutem que as diretrizes curriculares nacionais dos cursos de graduação em saúde, em sua maioria aprovadas, entre 2001 e 2002, definem que a formação do profissional de saúde deve contemplar o sistema de saúde vigente no país, o trabalho em equipe e a atenção integral à saúde, no entanto, constituem-se apenas uma indicação, uma recomendação. Apontam, ainda, que a educação dos profissionais de saúde apresenta uma abordagem biologicista, medicalizante e procedimentocentrada, em que o modelo pedagógico hegemônico de ensino é organizado de maneira compartimentada e isolada, fragmentando os indivíduos em especialidades da clínica, dissociando conhecimentos das áreas básicas e conhecimentos da área clínica (CECCIM; FEUERWERKER, 2004).

Muitas vezes, o usuário recebe informações fragmentadas ou até mesmo contraditórias, pois geralmente não tem um profissional, ou uma equipe que olhe para o todo. Em alguns momentos, o usuário pode até precisar de uma avaliação específica de algum profissional, ou mesmo ser atendido por um especialista. Mas a proposta de apoio é para além disso. É a busca de superar o trabalho individual, 
trazendo para a roda além do olhar de vários trabalhadores, o olhar do próprio usuário, para que, com o saber específico do trabalho, mas também com a experiência de vida, possam contribuir para um plano de cuidado que apoie o usuário para que ele leve a sua vida da maneira que desejar (FEUERWERKER, 2013).

Embora tivessem instituído um espaço de reunião para realização do apoio às eSF, este ainda era esvaziado, pouco aproveitado pelos trabalhadores que não compunham a equipe NASF

[...] pra iniciar o matriciamento mesmo, as reunióes, a gente tinha que ir conversar com a coordenadora, olha, vai acontecer isso na reunião; começar: pessoal vem cá, vai ter reunião de matriciamento. Então, a gente tinha que estimular, conversar, porque se não, não ia, e até hoje, na verdade, a gente tem que fazer isso para ter aquele dia lá, lembrete, cartazes, não sei o que, pisca-pisca luminoso [...] (Gérbera).

Havia predomínio da participação de uma categoria profissional que compunha a eSF, [...] ainda vejo na equipe, de um modo geral, as ACS mais participativas do que qualquer outra categoria. Mas tem unidade que nem a ACS "é laçada na marra”, é bem complicado [...] (Tulipa).

Com esse esvaziamento não havia a apropriação dos poucos momentos de encontro existentes no serviço. Ainda há uma cultura predominante de se manter a individualidade, focada na atuaçáo de especialistas, que recebem um encaminhamento, na discussão de caso, e assumem para si a responsabilidade de dar continuidade ao cuidado, sem que haja corresponsabilização entre equipes e profissionais no acompanhamento dos usuários.

Reuniốes às vezes não são valorizadas como espaço de produção de cuidado, por não ser um momento com o usuário, pode ficar em segundo plano. No entanto, o olhar de vários profissionais discutindo um caso, ou alguma situaçâo do território, embora não seja o cuidado produzido de forma direta, vai se reverter em benefício para o usuário, potencializando, então, o momento de cuidado em ato. A reuniáo pode ser vista como um momento que possibilita ampliar a caixa de ferramentas daqueles profissionais que participaram do processo de discussão, e que depois estarão mais bem preparados para lidar com as diferentes situaçôes e necessidades demandadas.

Merhy (1999) define caixa de ferramentas como o conjunto de saberes que se dispóe para a ação de produção dos atos de saúde. Todo trabalhador carrega consigo uma caixa de ferramentas com a qual opera no cotidiano do mundo do trabalho, portanto, quanto maior a composição das caixas de ferramentas utilizadas pelos trabalhadores de saúde, individualmente ou em equipes, maior será a possibilidade 
de se compreender o problema de saúde enfrentado e maior a capacidade de enfrentálo, tanto para o usuário do serviço quanto para a própria composiçáo dos processos de trabalho (MERHY, 1999).

Acrescenta-se ainda que pessoas se reunirem para discutir um caso, ou alguma situação, não é garantia de que esteja havendo uma produção de coletivo, é necessário que este seja um encontro intercessor. Merhy e Chakkour (1997) e Merhy (2002) denominam espaço intercessor como aquele em que cada uma das partes, trabalhador e trabalhador, ou trabalhador e usuário, coloca-se em toda sua inteireza; é o momento no interior do processo de trabalho em saúde, em que um se produz no outro e que depois os dois não são mais os mesmos, pois no encontro e em suas diferenças se transformaram num sujeito coletivo novo. E ao olhar esse encontro, pode-se interrogar/explicar muito a respeito de como é produzido o cuidado, sendo os espaços intercessores potentes para a transformação das práticas de saúde (LIMA, 2015).

Olhar para uma reunião como espaço produtor de cuidado é uma mudança de visão de como se pensa e se produz o cuidado, é um processo que precisa ser construído em conjunto, pois se não houver uma equipe que compreenda e valorize a intencionalidade do trabalho, e que não se apoie, o encontro perde sua potência enquanto espaço de produçáo de cuidado.

\section{Processos vividos para se produzir enquanto equipe... o encontro do cafezinho}

Embora pouco valorizado, o espaço formal de encontro era visto pela equipe NASF como local para se desenvolver o matriciamento. Momentos de conversa informal chegaram a ser citados, mas não sendo um momento potencial de encontro para realização/produção de apoio: “[...] mesmo com reuniâo (de matriciamento) falta bastante espaço. Não tem muito essa articulação não, acaba tendo mais é no meio da 'muvuca' mesmo, né, que conversa com um, conversa com outro, mas a questão de ser apoio... não sei [...]” (Tulipa).

Muitas das discussôes e articulações entre pares e equipe acontecem nos diversos espaços das unidades: no corredor, na cozinha, na hora do "cafezinho", enfim, no momento que dá certo, não sendo preciso, necessariamente, um ambiente formal para que a troca de informaçôes aconteça. Assim como a produção de um coletivo, também não ocorre somente nos espaços formais de reunião, mas nas conexôes estabelecidas diariamente em espaços informais, 
como, por exemplo, no trajeto às casas, dentro do carro, em uma visita domiciliar (LIMA, et al., 2016; MERHY e FEUERWERKER, 2008).

Conforme apontado por Merhy (2006), em geral, tanto nos espaços formais quanto nos informais, faz-se uma análise superficial ou unilateral da realidade e das situaçôes produzidas; porém, o movimento de ampliar os olhares pode ocorrer nos espaços formais, ou não, e nos espaços públicos ou privados, nas praças, rodas dos serviços de saúde, sem a necessidade de momentos específicos para que o apoio aconteça. Muitas coisas podem ocorrer na roda de conversa do café, onde há grande chance de alguns que estão ali serem envolvidos pelo que está sendo conversado e passarem a ver e a agir de outro modo em relaçáo aos casos (BADUY, 2010).

Também vale ressaltar que essa roda de conversa não pede licença para nenhum organograma oficial do serviço, nem para nenhuma hierarquia da organização. Ela vai acontecendo no agir do trabalho vivo em ato, nos espaços da organização, que os próprios trabalhadores (os gestores e os próprios usuários) vão fabricando com suas açôes conversacionais. Isso vai acontecendo. E nesse acontecer vai se produzindo conhecimento para a ação de um modo efetivo e isso impacta o mundo tecnológico do cuidado (MERHY, 2013b). Daí a potencialidade do encontro. Por meio dele, independentemente de onde se esteja, o apoio pode ser realizado. E é neste espaço, longe da formalidade e do preestabelecido, que muitas vezes o trabalho integrado realmente se faz.

\section{Consideraçôes finais}

Esta pesquisa foi realizada na vigência da portaria GM no 154 de 2008. Ainda assim, acreditamos que o processo discutido neste artigo não se modifica com as mudanças trazidas pela nova portaria. A implantação de novo processo de trabalho, nova equipe, com a absorção de novos profissionais, é e continuará sendo compartilhado e vivenciado por tantas outras equipes que passam pelo processo de se constituir enquanto coletivo organizado, dentro de um espaço com processos já instituídos e por vezes cristalizados. Sobre as diferenças entre as portarias, entendemos que a entrada de outros profissionais de saúde na $A B$ é, por si só, um grande ganho para o usuário do SUS. Acreditamos, porém, que o papel apoiador do NASF, fortemente valorizado na portaria de 2008, traz uma possibilidade de um novo rearranjo do processo de trabalho na Atenção Básica, tendo em vista um cuidado mais integral. 
A experiência dos pesquisadores neste trabalho mostrou que a equipe NASF estudada enfrentou vários desafios e buscou possibilidades para produzir momentos de encontro para que se constituísse enquanto coletivo e assim pudesse compartilhar os propósitos do trabalho e realizar o apoio às equipes de saúde da família. Tentou ocupar espaços de reuniôes já existentes, e não sendo possível, criou um espaço - a reunião de matriciamento - para promover o encontro entre equipe NASF e eSF, além de ter aproveitado os encontros informais nos corredores, no cafezinho, numa tentativa de construírem possibilidades de apoio.

Muitas vezes, as estratégias utilizadas nas reuniōes instituídas eram capturadas por discussōes centradas nos núcleos profissionais, sem problematizar a produção do cuidado e com baixa potência para transformar as práticas de saúde. Espaços de encontros informais se mostraram potentes para trocas de experiências, mas náo eram reconhecidos e valorizados para esta finalidade. Mesmo assim, eles aconteceram, mostrando o potencial existente no compartilhar de saberes de forma mais horizontal e solidária.

Nesse sentido, há que se pensar o quanto se tem avançado na compreensão de como produzir o trabalho em equipe e como realizar o apoio a estas equipes. Ficou evidente que não basta chamar de "equipe" para que o trabalho em equipe aconteça no cotidiano. É necessário que se desenvolva estratégias para construir relações de trabalho mais coletivas. Assim como não basta criar um espaço de encontro ou mesmo mudar o nome de uma reunião de trabalho já existente e continuar operando do mesmo modo, com reunióes predominantemente informativas. É preciso pensar para além da definição de horários e espaços físicos para os encontros. Torna-se fundamental também a definição de estratégias, técnicas de como produzir reuniôes formais que sejam encontros que transformem as práticas fragmentadas em práticas que produzam aprendizagem, corresponsabilização pelo cuidado, em que os participantes atuem efetivamente na dimensão cuidadora, ultrapassando os limites de seus núcleos profissionais.

Estas questôes devem ser uma preocupação das equipes NASF, mas não somente elas devem pensar em como colocar isso em prática, em como trazer os trabalhadores da $\mathrm{AB}$ para fazerem parte deste processo. Mais que isso, é necessário que aqueles que ocupam cargos de gestão do trabalho em saúde atuem de forma mais explícita para a produção do cuidado e do apoio, desenvolvendo dispositivos 
que atuem no sentido da produção do trabalho efetivamente como coletivos organizados, que não sejam apenas agrupamentos de diferentes profissionais onde cada um atue em seu núcleo profissional.

Para isso, ferramentas e instrumentos de gestão podem provocar os trabalhadores para que as reunióes de matriciamento não sejam só o cumprimento de funçôes burocráticas, mas que elas realmente se efetivem no âmbito do cuidado na relação com os usuários.

Outras estratégias podem ser mais utilizadas - por exemplo, a educação permanente em saúde -, contribuindo para que as reunióes se tornem espaços mais analíticos das potências e limitaçôes que os trabalhadores produzem nas situações de cuidado em que atuam, para além do encaminhamento dos usuários de profissional para profissional. A nosso ver, para que se produza cuidado, a equipe precisa se produzir enquanto coletivo. Para isso, é necessário que haja encontros intercessores onde os saberes, tantos os técnicos como os da vida, sejam compartilhados e os conflitos sejam enfrentados para que se produza um cuidado centrado no usuário, ampliando, com isso, suas possibilidades de apoiá-lo no seu modo de andar a vida. ${ }^{1}$

\section{Agradecimentos}

À Fundação Araucária, pelo financiamento concedido para realização da pesquisa, e à CAPES, pela bolsa de mestrado fornecida há uma das pesquisadoras.

\section{Referências}

BADUY, R. S. Gestão municipal e produção do cuidado: encontros e singularidades em permanente movimento. 2010. 185fl. Tese (Doutorado em Clínica Médica) - Faculdade de Medicina, Universidade Federal do Rio de Janeiro, Rio de Janeiro.

BERTUSSI, D. C. O apoio matricial rizomático e a produção de coletivos na gestão municipal em saúde. 2010. 243fl. Tese (Doutorado em Clínica Médica) - Faculdade de Medicina, Universidade Federal do Rio de Janeiro, Rio de Janeiro.

BRASIL. Ministério da Saúde. Politica Nacional de Atenção Básica. 4. ed. Brasília: MS, 2007. (Série Pactos pela Saúde, v. 4). . Portaria no 154 , de 24 de janeiro de 2008. Cria os Núcleos de Apoio à Saúde da Família - NASF. Brasília, DF: Diário Oficial da Uniâo: Ministério da Saúde, 25 jan. 2008. (Seção 1, ano CXLV, n. 18). 
. Ministério da Saúde. Secretaria de Atenção à saúde. Departamento de Atenção Básica. Caderno de Atenção Básica no 27. Diretrizes do NASF: Núcleo de Apoio a Saúde da Família. Brasília: Ministério da Saúde, 2010.

- Portaria no 2.488, de 21 de outubro de 2011. Aprova a Política Nacional de Atenção Básica, estabelecendo a revisão de diretrizes e normas para a organização da atenção básica, para a Estratégia Saúde da Família (ESF) e o Programa de Agentes Comunitários de Saúde (PACS). Brasília, DF, 2012. (Política Nacional de Atenção Básica. Série E. Legislação em Saúde).

- Portaria no 2.436, de 21 de setembro de 2017. Aprova a Política Nacional de Atenção Básica, com vistas à revisão da regulamentação de implantação e operacionalização vigentes, no âmbito do Sistema Único de Saúde - SUS, estabelecendo-se as diretrizes para a organização do componente Atenção Básica, na Rede de Atenção à Saúde - RAS. Brasília, DF, 2017.

CAMPOS, G. W. S. Equipes de referência e apoio especializado matricial: um ensaio sobre a reorganização do trabalho em saúde. Ciência e Saúde Coletiva. Abrasco, v. 4, n. 2, p. 393403, 1999.

CAMPOS, G. W. S.; DOMITTI, A. C. P. Apoio matricial e equipe de referência: uma metodologia para gestão do trabalho interdisciplinar em saúde. Cadernos de Saúde Pública. Rio de Janeiro, v. 23, n. 2, p. 399-407, fev. 2007.

CASTRO, C. P.; CAMPOS, G. W. S. Apoio Matricial como articulador das relaçóes interprofissionais entre serviços especializados e atenção primária à saúde. Physis: Revista de Saúde Coletiva. Rio de Janeiro, v. 26, n. 2, p. 455-481, 2016. Disponível em: <http://www. scielo.br/pdf/physis/v26n2/0103-7331-physis-26-02-00455.pdf>. Acesso em: 13 maio 2019.

CECCIM, R. B. Onde se lê recursos humanos da saúde, leia-se coletivos organizados de produção da saúde: desafios para a educação. In: PINHEIRO, R.; MATTOS, R. A. de (Orgs.). Construção social da demanda: direito à saúde, trabalho em equipe, participação e espaços públicos. 2. ed. Rio de Janeiro: CEPESC: UERJ: ABRASCO, 2005, p. 161-181.

CECCIM, R. B.; FEUERWERKER, L. C. M. Mudança na graduação das profissôes de saúde sob o eixo da integralidade. Cadernos de Saúde Pública. Rio de Janeiro, v. 20, n. 5, p. 1400-1410, set.-out., 2004.

CHIAVERINI, D. H. (Org.). Guia Prático de Matriciamento em Saúde Mental. Brasília, DF: BRASIL, Ministério da Saúde: Centro de Estudo e Pesquisa em Saúde Coletiva, 2011.

DOMITTI, A. C. P. Um possivel diálogo com a teoria a partir das práticas de apoio especializado matricial na atenção básica de saúde. 2006. 90fl. Tese (Doutorado em saúde coletiva) - Faculdade de Ciências Médicas, Universidade Estadual de Campinas, Campinas.

EPS EM MOVIMENTO. Cuidando de Ana Clara. 2014. Disponível em: <http://eps.otics.org/ material/entrada-textos-em-cena/cuidando-de-ana-clara/>. Acesso em: 20 jun. 2015. 
FEUERWERKER, L. C. M. A Atenção Domiciliar no município de Londrina. Universidade Federal do Rio de Janeiro. Micropolítica do Trabalho e o Cuidado em Saúde. 2008. Disponível em: <http://www.medicina.ufrj.br/micropolitica/pesquisas/atencaodomiciliar/textos.php>. Acesso em: 05 mar. 2016.

. Cuidar em saúde. Caderno de Textos: Ver-SUS. Porto Alegre: Rede Unida, v. 1, p. 43-57, 2013.

FRANCO, T. B.; MERHY, E. E. Programa de Saúde da Família (PSF): contradiçóes de um programa destinado à mudança do modelo tecnoassistencial. In: MERHY, E. E. et. al. $O$ trabalho em saúde: olhando e experienciando o SUS no cotidiano: o debate no campo de saúde coletiva. 4. ed. São Paulo: Hucitec, 2007.

GIL, C. R. R. Atenção primária, atenção básica e saúde da família: sinergias e singularidades do contexto brasileiro. Caderno de Saúde Pública. Rio de Janeiro, v. 22, n. 6, p. 1171-1181, jun. 2006. Disponível em: <http://www.scielosp.org/pdf/csp/v22n6/06.pdf> Acesso em: 1 mai. 2019.

LIMA, J. V. C. A produção do cuidado na atenção básica: controlar a vida/produzir a existência. 2015. Tese (Doutorado em Ciências) - Faculdade de Medicina da Universidade Federal do Rio de Janeiro, Rio de Janeiro, 2015.

LIMA, J. V. C. et al. Produção de Coletivos. In: MERHY, E. E. (Org.). Avaliação compartilhada do cuidado em saúde: Surpreendendo o instituído nas redes. Rio de Janeiro: Hexis editora, 2016, p. 390-393.

MEDEIROS, R. H. A. Uma noção de matriciamento que merece ser resgatada para o encontro colaborativo entre equipes de saúde e serviços no SUS. Physis: Revista de Saúde Coletiva. Rio de Janeiro, v. 25, n. 4, p. 1165-1184, 2015.

MERHY, E. E. A perda da dimensão cuidadora na produção da saúde: Uma discussão do modelo assistencial e da intervenção no seu modo de trabalhar a assistência. In: CAMPOS, C. R. et al. Sistema Único de Saúde em Belo Horizonte - reescrevendo o público. São Paulo: Editora Xamã, 1998, p. 103-120.

. O Ato de Cuidar: a alma dos serviços de saúde. DMPS/ FCM/ UNICAMP - 1999. Disponível em: <https://www.pucsp.br/prosaude/downloads/territorio/o-ato-de-cuidar.pdf>. Acesso em: 2 mai. 2019.

. Saúde: cartografia do trabalho vivo. São Paulo: Hucitec, 2002.

_. Público e privado: entre aparelhos, rodas e praças. Campinas, fev. 2006. Disponível em: $<$ http://www.saude.campinas.sp.gov.br/saude/carta_da_saude/ed_16_artigo.PDF>. Acesso em: 2 maio 2019.

. (Coord.). A produção do cuidado em diferentes modalidades de Redes de Saúde, do Sistema

Único de Saúde: Avalia quem pede, quem faz e quem usa. Brasília, DF: SAS-MS, out. 2013a. (Relatório Final.) 
. Educação Permanente em Movimento: uma política de reconhecimento e cooperação, construindo encontros no cotidiano das práticas de saúde. Porto Alegre: MS, 2013b.

MERHY, E. E.; CHAKKOUR, M. Em busca de ferramentas analisadoras das tecnologias em saúde: a informação e o dia-a-dia de um serviço, interrogando e gerindo trabalho em saúde. In: MERHY, E. E.; ONOCKO, R. (Orgs.). Agir em Saúde: um desafio para o público. São Paulo: Hucitec, 1997, p. 113-150.

MERHY, E. E.; FEUERWERKER, L. C. M. Atenção Domiciliar: medicalização e substitutividade. Universidade Federal do Rio de Janeiro, 2008. Micropolítica do Trabalho e o Cuidado em Saúde. Disponível em: <http://www.medicina.ufrj.br/micropolitica/pesquisas/ atencaodomiciliar/textos.php>. Acesso em: 7 mar. 2016.

- Novo olhar sobre as tecnologias de saúde: uma necessidade contemporânea. In: MANDARINO, A. C. S.; GOMBERG, E. (Org.). Leituras de novas tecnologias e saúde. Salvador: UFBA, 2009, p. 29-56.

OLIVEIRA, M. M.; CAMPOS, G. W. S. Apoios matricial e institucional: analisando suas construções. Ciênc. Saúde Coletiva. Rio de Janeiro, v. 20, n. 1, p. 229-238, 2015. Disponível em: <http://www.scielo.br/pdf/csc/v20n1/pt_1413-8123-csc-20-01-00229.pdf>. Acesso em: 13 mai. 2019.

TRAD, L. A. B. Grupos focais: conceitos, procedimentos e reflexôes baseadas em experiências com o uso da técnica em pesquisas de saúde. Physis: Revista de Saúde Coletiva. Rio de Janeiro, v. 19, n. 3, p. 777-796, 2009. Disponível em: <http://www.scielo.br/pdf/physis/v19n3/a13v19n3. pdf $>$. Acesso em: 1 mai. 2019.

\section{Nota}

${ }^{1}$ K. S. de Oliveira realizou pesquisa de campo, coleta, análise e interpretação dos dados, redação e revisão do artigo. R. S. Baduy e R. Melchior realizaram análise e interpretação dos dados, redação e revisão do artigo. 


\section{Abstract}

\section{The meeting between the Family Health}

Support Center and the Family Health teams:

the production of a caring collective

The Family Health Support Center (NASF) was created with the purpose of reorganizing health care and assisting in the qualification of SUS. The organization of the work process of the NASF depends on the existence of collective spaces, moments of meetings in which workers can be together to implement more qualified actions, increasing the resolving capacity of the teams. This article aims to analyze the processes experienced by the NASF team to produce moments of encounter as a means of producing support for family health teams. It is a research of qualitative approach type, which used work observation and focal group in the field. As results are presented the processes experienced by the NASF team for the collective production, describing how the space of the matrix meeting was constructed and the contributing processes, as informal moments of meetings, such as coffee time. The NASF team looked for integration alternatives, however their practice was captured by the operative work process and by the hegemonic model. The bet on intercessory encounters, where both technical and life skills are shared, is a way to be followed in the production of collectives.

> Keywords: Family Health; support; collective production; health care. 